\title{
Survey on the Impact of VAT on Libraries and the Scientific Publication Markets
}

\author{
by SOZIOLOGISCHES FORSCHUNGSINSTITUT GÖTTINGEN (SOFI) E.V.
}

Final Report Carried out by Soziologisches Forschungsinstitut Göttingen (SOFI) e.V. an der Georg-AugustUniversität on behalf of the Frankfurt Group April - May 2006

\section{BACKGROUND AND GOAL OF THE STUDY}

Within the European Union (EU), printed and electronic versions of publications are treated differently. Whereas books, newspapers and periodicals are subject to a reduced rate of VAT, electronic publications, of all types, are charged with the full rate of VAT [1]. These regulations have several consequences for European libraries and the market for scholarly publications in Europe, not least in regard to the change from printed to electronic publications.

On the one hand, as a direct consequence of higher costs for electronic publications, this influences the libraries' decision when purchasing resources. As the European Commission states in a recent study, the different VAT rates lead to a situation, where it is cheaper for libraries to order printed versions of resources in addition to the electronic version even if it is only the electronic version that is considered valuable [2]. Despite the negative welfare effects, it also has detrimental effects on the transition from printed to electronic publications.

On the other hand, due to the differences in standard and reduced rates of VAT within the member states of the EU, libraries in the EU face completely different economic situations concerning their effective budget when purchasing resources, depending on national legislations. This does not only affect the provision of knowledge within the EU, it also affects the development of science in the EU as a whole, compared to countries without VAT charges on electronic publications like the USA.

So, VAT issues are a key problem in the current development of the framework of scientific publications in Europe. The Frankfurt Group has therefore commissioned this survey in order to show the impact of current VAT regulations on the resources available for libraries to support research and education on the one hand, and on the competitive position of EU publishing, education and research on the other hand. As the problem of VAT in general is well known, the main goal of this survey has been to prepare as precise data as possible, to quantify the impact of VAT on the libraries' budgets.

\section{THE CHARACTER OF THE SURVEY}

The survey undertaken consisted of a personalized online-questionnaire, which was accessible to the 265 European members of LIBER serving as the population for the survey. Figure 1 gives an overview about the invited libraries grouped by countries. 


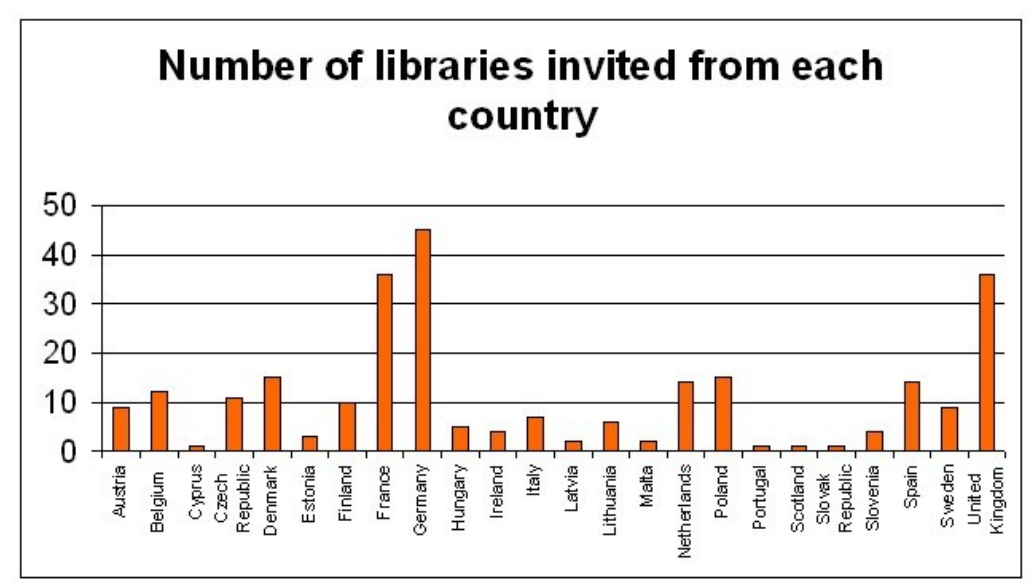

Figure 1

The questionnaire consisted of two main parts. The first part comprised several tables, the participants were to fill out, concerning the disposition of the libraries' budget in the last three years in respect of the acquisition of printed and electronic resources as well as printed \& electronic bundles. The data to be provided was the total amount of the budget spent, the amount of VAT paid and the number of items, the budget was spent on.

Two additional tables for every year were to generate more detailed data for the electronic resources and the print \& electronic bundles, as they asked for the disposition of the budget for special forms of these resources (journals, series, etc.).

There were also two questions concerning the transition from printed to electronic publications, followed by some simple questions concerning the national VAT regulations.

The survey started on April $7^{\text {th }}$ 2006. Due to lack of participation, two follow-up mails were sent (April $20^{\text {th }}$ and $29^{\text {th }}$ ), the latter in combination with a slight change of the questionnaire. A lot of respondents stopped completing the questionnaire when they reached the tables concerning the libraries' budgets on the second page. Therefore we pushed these tables to the last part of the questionnaire, thereby hoping to get at least some answers on the questions concerning the national VAT regulations. We also included the possibility of providing individual comments on the questionnaire in order to gain an impression of the problems with the questionnaire. The dataset, this report is based on, was generated on May $16^{\text {th }} 2006$.

\section{OBTAINED DATA}

The responses to the survey showed, that there was a great interest in the subject of the survey, 138 of the 265 invited participants opened the questionnaire $(52,08 \%)$. But the willingness to answer and return the requested data was rather low, only 42 completed the questionnaire $(15,85 \%)$, and this does not mean that they answered all the questions. Those participants just made it to the last page. Figure 2 shows the development of participation over the time the questionnaire was active. 


\section{Development of participation}

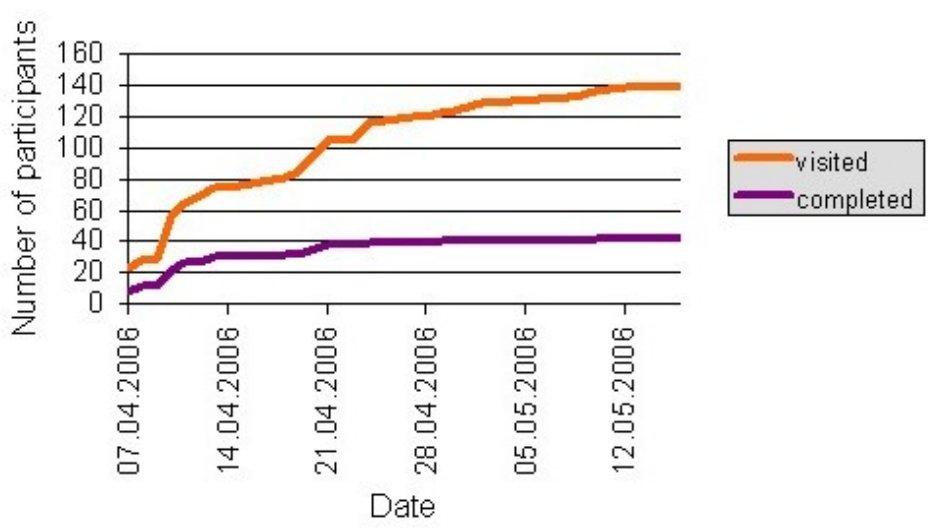

Figure 2

The vast majority of the libraries that have completed the questionnaire are libraries connected to universities (figure 3), libraries or research institutes not linked to universities play a minor role.

\section{Type of library}

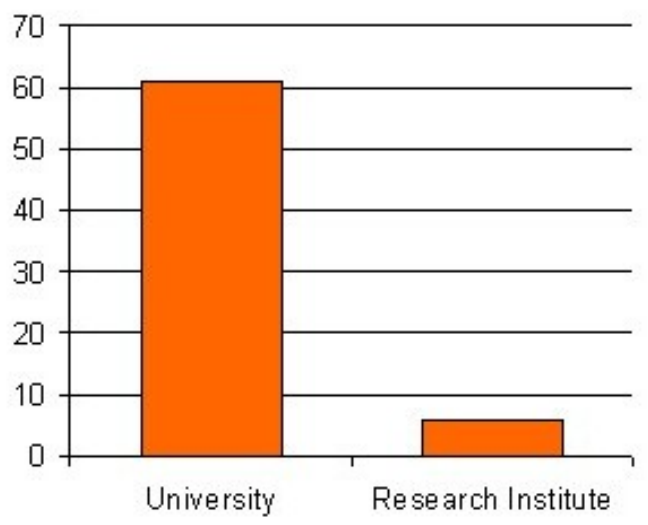

Figure 3

As figure 4 shows, the majority of the responses came from Germany and the UK. Many countries are only represented by a single participant. So the knowledge we gathered about the different VAT regulations is of very different quality. Some countries with complicated national VAT regulations cannot be described in all details on the basis of this data. 


\section{Number of participated libraries grouped by country}

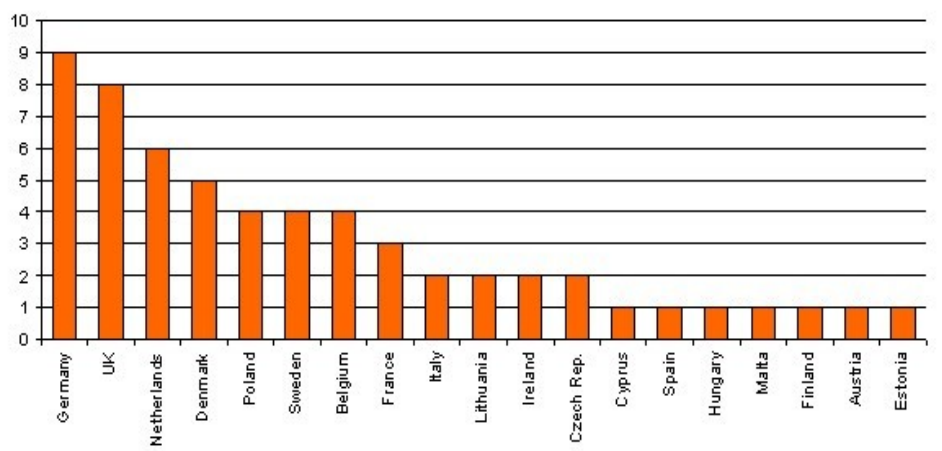

Figure 4

\section{RESULTS: NATIONAL DIFFERENCES CONCERNING VAT}

Although EU VAT regulations mean that electronic publications are subject to full VAT rates, there are some Member States with special national VAT regulations that circumvent this fact.

In Denmark, for example, all state and local government institutions do not pay VAT. So all state libraries are also completely VAT exempt. The situation in Sweden and Austria is very similar to this in that libraries are reimbursed the whole VAT expenditure once a year.

Besides that, there are countries like the Czech Republic and Lithuania that have founded VAT exempt national consortia, where libraries can obtain resources from without paying VAT. A special case is the UK, because some libraries have outsourced a part of the library as a company, what makes it possible to reclaim a certain part of VAT. This case seems to be very complicated and the obtained data does not present further details about these special regulations.

The largest part of European libraries are not exempt from VAT, so libraries of these countries have to pay full VAT charges on electronic resources.

Table 1 shows the differences in Europe concerning effective VAT rates to be paid by European libraries as gathered from the data in this survey.

\begin{tabular}{|l|l|l|}
\hline $\begin{array}{c}\text { Countries with } \\
\text { complete VAT } \\
\text { exemption for libraries }\end{array}$ & $\begin{array}{c}\text { Countries with special } \\
\text { tactics concerning } \\
\text { VAT }\end{array}$ & $\begin{array}{c}\text { Countries in which } \\
\text { libraries have to pay } \\
\text { full VAT rates }\end{array}$ \\
\hline $\begin{array}{l}\text { Austria (VAT is } \\
\text { reimbursed) }\end{array}$ & $\begin{array}{l}\text { Czech Republic } \\
\text { (national consortium for } \\
\text { electronic resources) } \\
\begin{array}{l}\text { Denmark (real VAT } \\
\text { exemption) }\end{array}\end{array}$ & $\begin{array}{l}\text { Germany } \\
\text { Italy } \\
\text { Spain }\end{array}$ \\
$\begin{array}{l}\text { Sweden (VAT is (consortium } \\
\text { reimbursed) }\end{array}$ & UK (companies) & $\begin{array}{l}\text { Ireland } \\
\text { Malta } \\
\text { Belgium } \\
\text { Netherlands }\end{array}$ \\
\hline
\end{tabular}

Table 1 
These differences within Europe concerning VAT charges lead to different situations for European libraries in comparison to each other. Figure 5 shows the relation between the VAT exempt and non VAT exempt libraries (from the data provided by the participating libraries), as this is an important dimension when interpreting our results. We can see quite clearly that the question of payment of VAT when purchasing electronic materials influences the decisions in relation to the change from print to electronic resources.

\section{Is your institution \\ VAT exempt \\ under your \\ national VAT \\ regulations?}

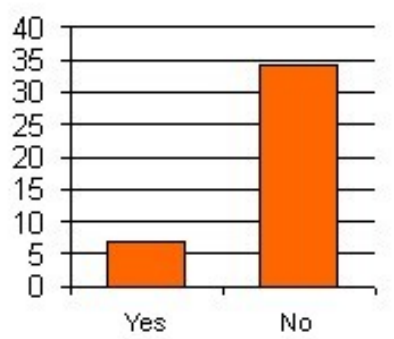

Figure 5

In Figure 6 we can see that this difference is an important dimension when analysing the results of our survey and the answers on the question about the consequences, the provision of all electronic resources in electronic form would have on the amount of VAT paid by the institution.
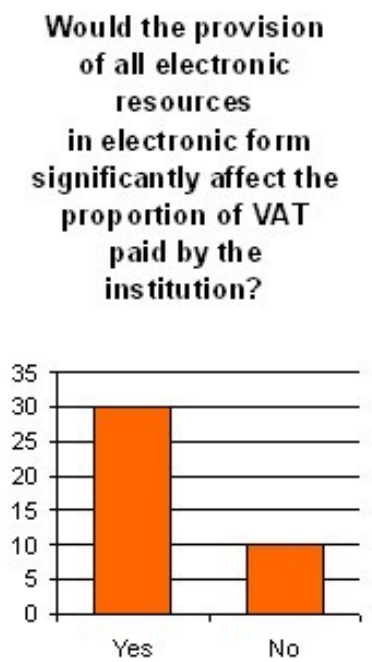

Figure 6

So, of course, for institutions that are VAT exempt this does not matter at all. This conclusion is qualified when looking at the answers on the question about the main hindrances, that are to be overcome in the switch to electronic format [3] (figure 7-13). The question of VAT is, in this context, most often mentioned as the most important hindrance on the one hand, but on the other hand also comes second as an absolutely unimportant hindrance. 
Electronic version

not available

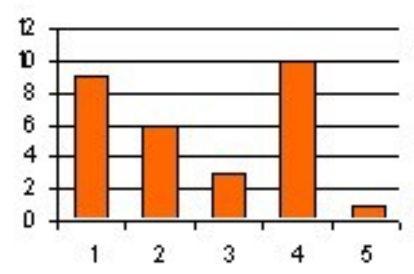

Figure 7

\section{Increased costs}

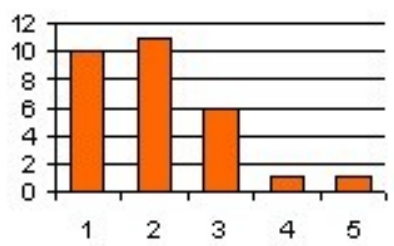

Figure 10

\section{Budget reduction}

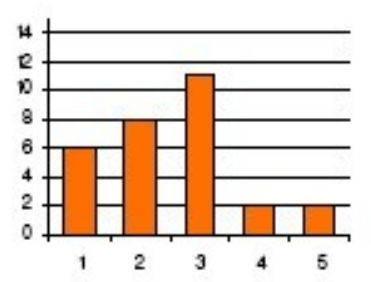

Problerns with

managem ent and

access of the

electronic infomation

sources

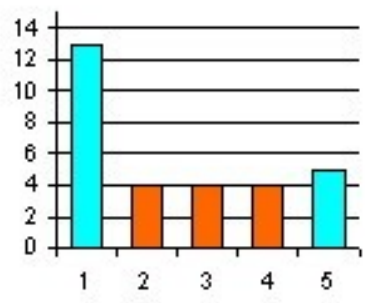

Figure 8
Figure 9

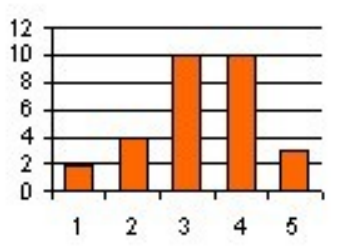

\section{User resistance}

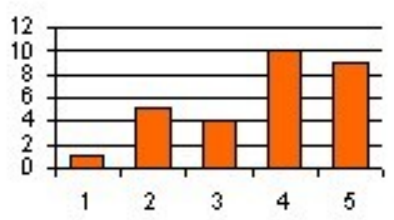

Figure 11
Problems with digital

preservation

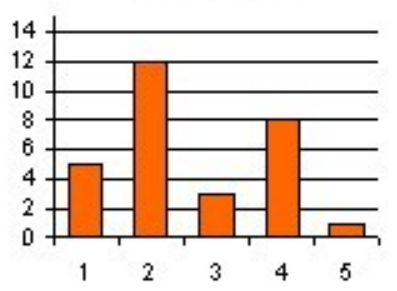

Figure 12

Figure 13

So the contradictory perspectives of institutions that are VAT exempt and those that are not are noticeable in our results. This gets even clearer when looking at the following two figures, which illustrate the different perspectives of the VAT exempt and non exempt libraries in regard to the hindrances in the change to electronic resources (see figure 14 and 15). 
Hindrances considered to be the most important by VAT exempt libraries
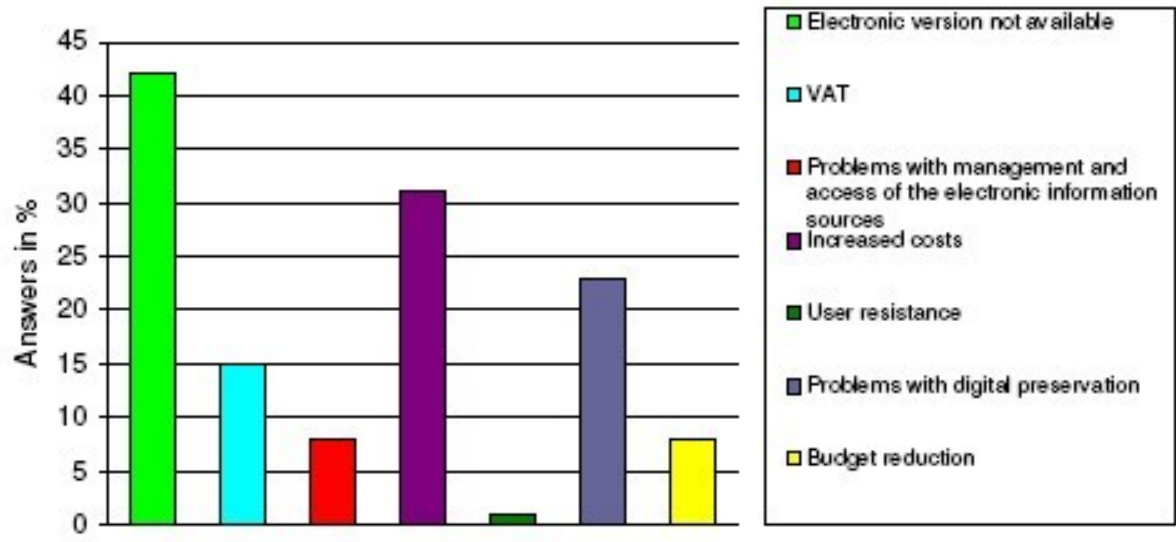

Figure 14

Hindrances considered to be the most important by non VAT
exempt libraries

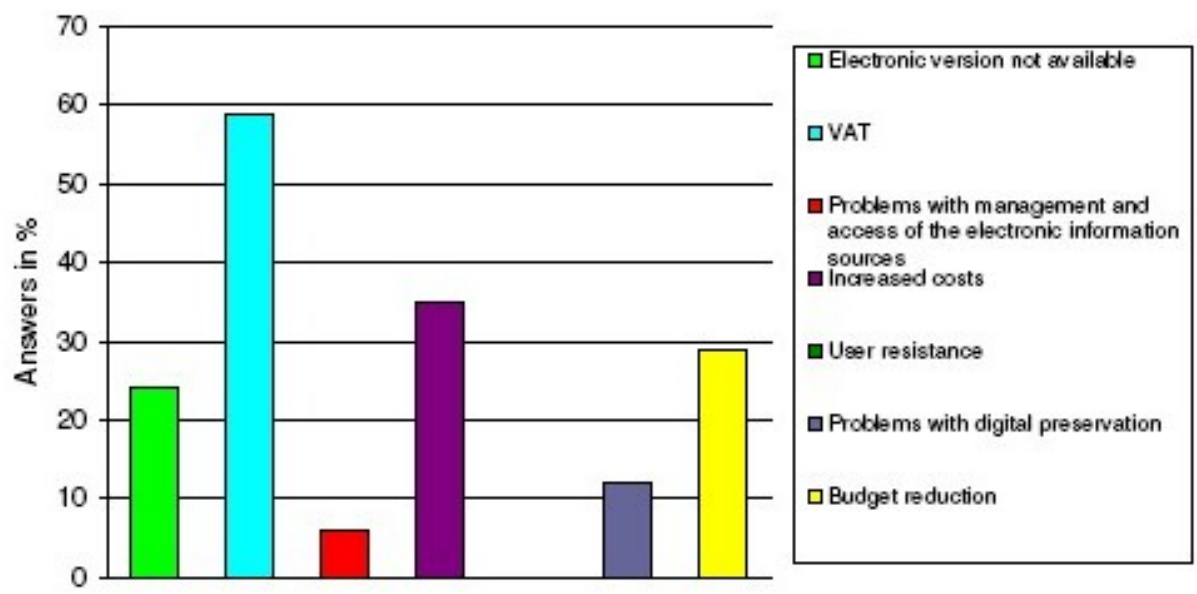

Figure 15

These two figures show the difference, the VAT exemption has on the perceived hindrances in the switch to electronic format. And they help to understand the polarized results we get when looking at the results not differentiated in these two groups of libraries. For the non VAT exempt institutions the matter of VAT is the most important hindrance $(59 \%$ of the non VAT exempt participants ranked this hindrance as very important). For the VAT exempt libraries, the matter of VAT is of course not the dominant one, as the majority of the participants ranked the not always given availability of electronic resources first $(42 \%$ of the VAT exempt participants considered this hindrance to be very important, just $15 \%$ did so concerning VAT).

\section{IMPACT OF VAT EXEMPTION ON THE SWITCH TO ELECTRONIC RESOURCES}

It stands to reason, that the different situations also influence the development of the allocation of electronic resources by European libraries over the last few years. The comparison of an German (non-VAT exempt) and a Danish (VAT 
exempt) library of similar budgets gives force to the assumption, that there is a relation between VAT exemption and the successful switch to electronic resources (see figure 16 and 17).
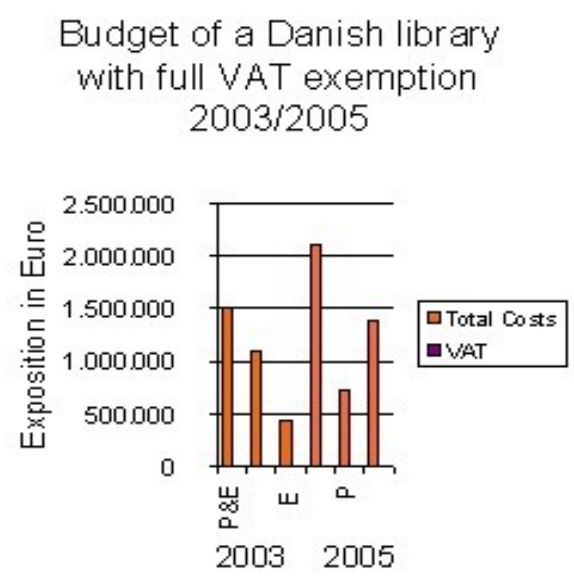

Figure 16

\section{Budget of a German library \\ without VAT exemption \\ $2003 / 2005$}

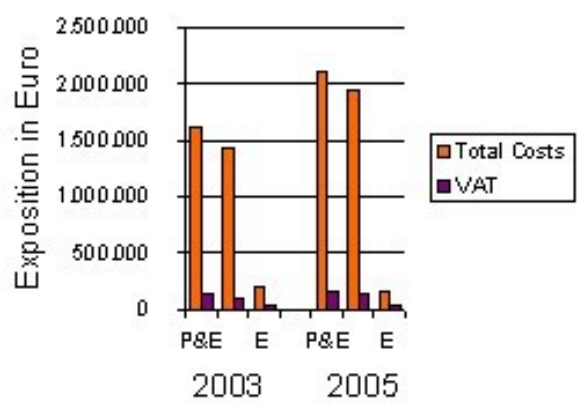

Figure 17

From 2003 to 2005 the Danish library changed the disposition of its budget and by 2005 a larger part of the budget was spent on electronic resources, whereas the German library did not make this change over the same period of time.

But a closer look at the different libraries reveals, that this development is much more complex and that there are other factors influencing the potential switch to electronic resources.

There are also VAT exempt libraries that did not significantly enlarge the portion of electronic resources in relation to print, as figure 18 shows for a Lithuanian library (VAT exempt for electronic resources due to subscription via national consortium). It shows the limitations of the consortial concept with a restricted number of licenses.
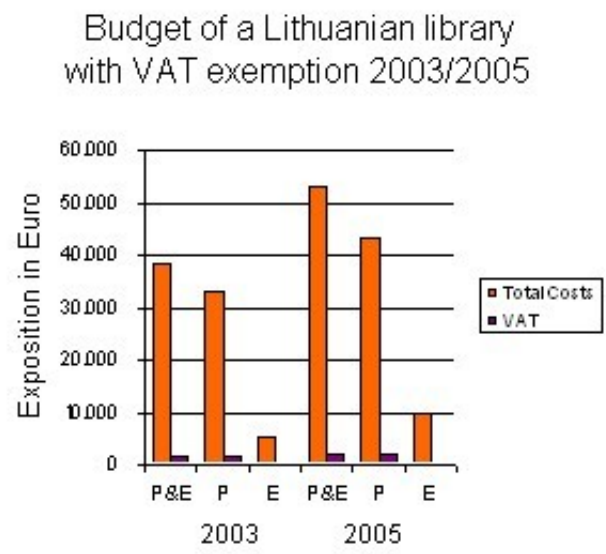

Figure 18

On the other hand the development of the budget allocation of a Czech library (in this case, it is a library, that does not participate in the Czech national consortium for electronic resources and so has to pay full VAT rates for its electronic resources) and a Belgian library (also non VAT exempt) shows increasing electronic expenses. 


\section{Budget of a Belgian library without VAT exemption $2003 / 2005$}

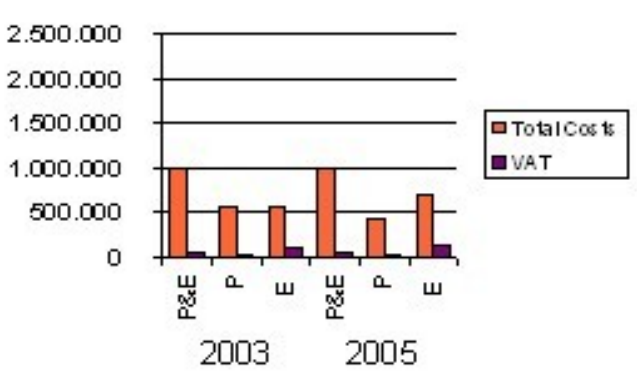

Figure 19

\section{Budget of a Czech library without VAT exemption $2003 / 2005$}

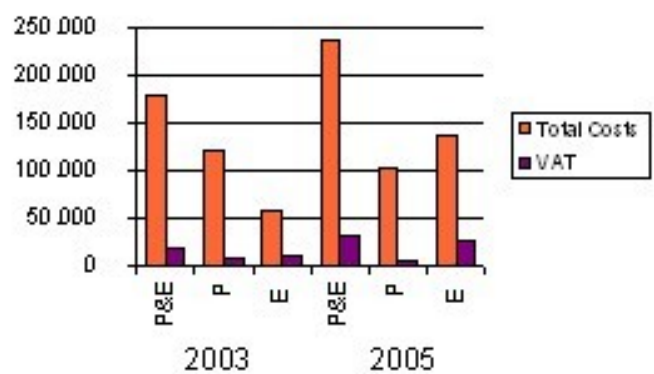

Figure 20

Both libraries show an increase in the budget for electronic resources in 2005 compared to the budget for printed resources. In the case of the Czech library, this was not the case in 2003, in the Belgian library increased spending for electronic resources from 2003 to 2005 in relation to printed material.

All in all, libraries with increases of budget disposition from printed resources to electronic resources are special cases within the results of our survey. For the vast majority of European libraries, the biggest part of the libraries' budget is still spent for printed resources. Figure 21 shows a final example of a big German library without VAT exemption.
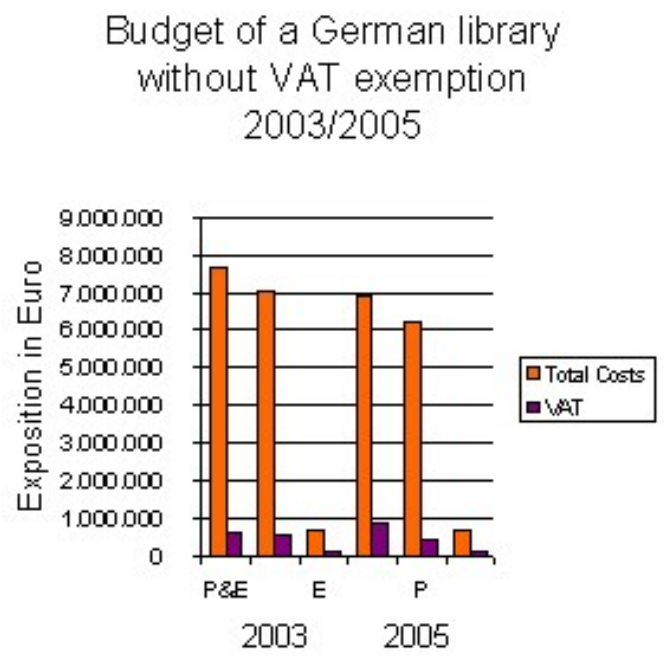

Figure 21

\section{CONCLUSION: THE IMPACT OF VAT ON THE SWITCH TO ELECTRONIC PUBLICATIONS}

The original goal of this survey was the generation of quantitative data concerning the impact of VAT on European libraries' budgets and the consequences for the ongoing change from printed to electronic publications.

As the figures 7-13 show, VAT is the factor, which is considered the most important hindrance to be overcome by European librarians in this process. 
As the figures about the development of the libraries' budgets in VAT exempt and non exempt countries show, VAT is not the only factor in this process. The level of participation in the survey means that there are limits to the interpretation of the results, so that we were not able to draw conclusions about the relation of the VAT matters to other factors in this process, that might have given a much more precise picture of the impact of VAT in the specific national cases. However we can provide some quantifiable data concerning the burden, VAT represents for the majority of European libraries as the figures about the libraries' budgets show.

\section{NOTES}

1. For an overview about different rates of VAT within the EU see: VAT-Rates applied in the member states of the European community - Situation at 1st February 2006.European Commission Directorate-General, Taxation and Customs Union, Brussels, DOC/1803/2006-EN, in: http://europa.eu.int/comm/taxation_customs/resources/documents/taxation/vat/how vat_works/rates/vat rate s 2006 en.pdf, page 55 .

2. Study on the economic and technical evolution of the scientific publication markets in Europe, in http://ec.europa.eu/research/science-society/pdf/scientific-publication-study en.pdf

3. In this question 1 means very important, 5 stands for absolutely unimportant.

\section{WEBSITES REFFERED TO IN THE TEXT}

LIBER: http://www.kb.dk/liber/ 


\section{APPENDIX. LIST OF FIGURES AND TABLES}

Figure 1: Number of libraries invited from each country

Figure 2: Development of participation

Figure 3: Type of library

Figure 4: Number of participated libraries grouped by country

Figure 5: Answers on question concerning VAT exemption

Figure 6: Answers on question concerning the effect of the provision of electronic resources in electronic form on VAT to be paid

Figure 7: Hindrances in the change to electronic form 1

Figure 8: Hindrances in the change to electronic form 2

Figure 9: Hindrances in the change to electronic form 3

Figure 10: Hindrances in the change to electronic form 4

Figure 11: Hindrances in the change to electronic form 5

Figure 12: Hindrances in the change to electronic form 6

Figure 13: Hindrances in the change to electronic form 7

Figure 14: Hindrances considered to be the most important by non VAT exempt libraries

Figure 15: Hindrances considered to be the most important by VAT exempt libraries

Figure 16: Budget of a Danish library with full VAT exemption 2003/2005

Figure 17: Budget of a German library without VAT exemption 2003/2005

Figure 18: Budget of a Lithuanian library with VAT exemption 2003/2005

Figure 19: Budget of a Belgian library without VAT exemption 2003/2005

Figure 20: Budget of a Czech library without VAT exemption 2003/2005

Figure 21: Budget of German library without VAT exemption 2003/2005 